\title{
SUSTENTABILIDADE E EDUCAÇÃO: PAPEL DO CIDADÃO LEVANDO-SE EM CONSIDERAÇÃO AS IDEIAS DE AMARTYA SEN
}

\author{
Beatriz Rolim Cartaxo ${ }^{1}$
}

\begin{abstract}
Resumo: O presente artigo tem como objetivo central abordar a relação existente entre educação, cidadania e sustentabilidade analisando os fatores que envolvem a função de cada cidadão na sustentabilidade levando em consideração as ideias de Amartya Sen. Elaborou-se uma fundamentação teórica, com o intuito de aprofundar o conhecimento sobre o assunto proposto nesse trabalho, base para uma metodologia que envolve a análise conceitual de educação e sustentabilidade ambiental, enfatizando a importância do papel de cada um no alcance da sustentabilidade do meio ambiente. A metodologia deste trabalho foi concretizada através de uma pesquisa exploratória baseada no levantamento de referencial bibliográfico, proporcionando o conhecimento necessário para a conclusão do trabalho. Assim, espera que o trabalho seja de leitura prazerosa e que contribua de maneira construtiva para o aprofundamento do tema.
\end{abstract}

Palavras-chave: Democracia; Educação; Sustentabilidade.

\section{SUSTAINABILITY AND EDUCATION: THE ROLE OF THE CITIZEN TAKING INTO CONSIDERATION THE IDEAS OF AMARTYA SEN}

\begin{abstract}
This article aims to address the relationship between education, citizenship and sustainability by analyzing the factors that involve the role of each citizen in sustainability taking into account the ideas of Amartya Sem. A theoretical basis was elaborated with the intention of deepening The knowledge about the subject proposed in this work, the basis for a methodology that involves the conceptual analysis of education and environmental sustainability, emphasizing the importance of the role of each one in the achievement of the sustainability of the environment. The methodology of this work was accomplished through an exploratory research based on the bibliographical reference survey, providing the necessary knowledge for the conclusion of the work. Thus, he hopes that the work will be enjoyable reading and contribute in a constructive way to the deepening of the theme.
\end{abstract}

Keywords: Democracy; Education; Sustainability.

\footnotetext{
${ }^{1}$ Mestranda em Direito e Desenvolvimento Sustentável pelo Centro Universitário de João Pessoa - UNIPÊ. Bacharel em Direito pelo Instituto Superior da Paraíba - IESP.
} 


\section{INTRODUÇÃO}

A sustentabilidade resulta de um processo de educação pela qual o ser humano redefine o feixe de relações que entretém com o Universo, com a Terra, com a natureza, com a sociedade e consigo mesmo dentro dos critérios de equilíbrio ecológico, de respeito e amor à Terra e à comunidade de vida, de solidariedade para com as gerações futuras e da construção de uma democracia sócio ecológica sem fim.

Somente um processo generalizado de educação pode criar novas mentes e novos corações, capazes de fazer a revolução paradigmática exigida pelo risco global sob o qual se vivem. Agora todas as pessoas são urgidas a mudar. Não cabe aqui abordar a educação em seus múltiplos aspectos tão bem formulados em 1996 pela UNESCO: aprender a conhecer, a fazer, a ser e a viver juntos; eu acrescentaria aprender a cuidar da Mãe Terra e de todos os seres.

Mas este tipo de educação é ainda insuficiente. A situação mudada do mundo exige que tudo seja ecologizado, isto é, cada saber deve prestar a sua colaboração a fim de proteger a Terra, salvar a vida humana e o projeto planetário. Portanto, o momento ecológico deve atravessar todos os saberes.

A 20 de dezembro de 2002 a ONU aprovou uma resolução proclamando os anos de 2005-2014 a Década da educação para o desenvolvimento sustentável. Neste documento se definem 15 perspectivas estratégicas em vista de uma educação para sustentabilidade. São algumas delas: Perspectivas socioculturais que incluem: direitos humanos, paz e segurança; igualdade entre os sexos; diversidade cultural e compreensão intercultural; saúde; AIDS; governança global. Perspectivas ambientais que comportam: recursos naturais (água, energia, agricultura e biodiversidade); mudanças climáticas; desenvolvimento rural; urbanização sustentável; prevenção e mitigação de catástrofes. Perspectivas econômicas que visam: a redução da pobreza e da miséria; a responsabilidade e a prestação de contas das empresas.

Como se depreende, o momento ecológico está presente em todas as disciplinas: caso contrário não se alcança uma sustentabilidade generalizada. Depois que irrompeu o paradigma ecológico, conscientizou-se do fato de que todos são eco dependentes. Participam de uma comunidade de interesses com os demais seres vivos que compartem a biosfera. O interesse comum básico é manter as condições para a continuidade da vida e da própria Terra. É o fim último da sustentabilidade. Logo, o presente trabalho tenta responder o seguinte 
questionamento: existe relação entre educação, cidadania e sustentabilidade segundo as ideias de Amartya Sen?

Dessa forma, o trabalho almeja analisar os conceitos produzidos por essa relação produzidos pela literatura e por Amartya Sen o qual propõe que o crescimento econômico sirva a liberdade, e o crescimento de mercado e suas ramificações sejam instrumentos pelos quais as populações implementem condição de homem e mulheres livres. O desenvolvimento, não é só econômico, é também um conjunto de benefícios acessíveis a todos os indivíduos.

Em relação aos aspectos metodológicos, o presente artigo apresenta natureza qualitativa. O método de abordagem utilizado neste trabalho será hipotético-dedutivo. Quanto aos métodos de procedimento, serão empregados o método histórico, o comparativo e o interpretativo, pois o trabalho abarca a ideia de progressão do ordenamento jurídico, buscando acompanhar as necessidades sociais atuais. A classificação adotada com base nos procedimentos técnicos possui caráter teórico-bibliográfico, pois a pesquisa exigiu a coleta de material (livros, periódicos, textos e documentos), buscados em bibliotecas universitárias e acervo pessoal.

\section{BRASIL: CAMINHOS RUMO AO DESENVOLVIMENTO SEGUNDO AMARTYA} SEN

Para se analisar a construção da cidadania no Brasil, deve-se interpretá-la à luz de uma sociedade escravocrata com um sistema agrário-exportador, herdados de uma matriz Ibérica, que buscava aplicar em suas colônias um modelo de exploração e não de ocupação integrada dos espaços.

Segundo Paiva ${ }^{2}$, dentre os traços predominantes de organização social pode-se apontar:

- hierarquização na ordem social,

- organicidade na concepção de mundo,

- o patriarcalismo inscrito nas relações sociais,

- o autoritarismo na esfera pública.

O Brasil teria passado por uma modernização seletiva, onde se inscreveram desigualdades sociais, em que uma minoria retinha a maior parte da riqueza forjada pelos braços da maioria trabalhadora, além disso, o Brasil foi composto a partir de uma lógica de extremas desigualdades regionais, onde o campo foi esquecido e os direitos valiam apenas para os trabalhadores moradores dos centros urbanos.

\footnotetext{
${ }^{2}$ PAIVA, Ângela M. de Randolpho. Direitos, desigualdade e acesso à universidade. In: Revista O Social em Questão. PUC/Rio, 2010. p. 20.
} 
Portanto, afirma Paiva ${ }^{3}$, “a história republicana brasileira contém um déficit para a construção de uma ordem social democrática que possa ser vista como instância de participação e exercício da cidadania".

Assim sendo, "cidadania no Brasil era um ideário exclusivo a alguns grupos a quem foi permitido acesso a bens sociais, à justiça, à educação e ao trabalho regulado"4 .

$\mathrm{O}$ autor supracitado afirma ainda que,

(...) a formação de uma esfera pública excludente e superposta por interesses privados; uma ordem jurídica formal a prometer sempre justiça num futuro impreciso; uma ordem social injusta, (em) que um suposto desenvolvimento econômico viria, um dia, resolver essa questão social; e, finalmente, uma ordem política autoritária, a privilegiar mecanismos de forte controle social, inclusive militar, nos momentos em que ocorreram conflitos, numa dimensão que a sociedade brasileira não pode suportar, viabilizaram uma forma de cidadania esquizofrênica, a o que a autora denomina "cidadania disjuntiva"

A questão central para Dagnino ${ }^{6}$ é a da presença da dimensão cultural na luta política no Brasil, isto é, na constituição da cultura como um fato político e seus efeitos na luta por democratização, construção de esferas públicas e exercício de cidadania.

Dessa forma, o autor acima polemiza as análises sobre democracia na região, para ele "as análises predominantes da democracia centram-se no que os cientistas políticos batizaram de 'engenharia institucional', requisito para a consolidação da democracia representativa no Sul das Américas"7.

No início da transição do autoritarismo político para a democracia, os Movimentos Sociais e os Sindicatos passam a ocupar um terreno de lutas que além de almejar liberdades individuais, lutam por participação nos encaminhamentos políticos e por justiça social no Brasil. Cidadãos passam a expor e reclamar da situação em que vivem, apontando preconceitos raciais, de renda, de gênero, etc.

O desafio era o de ampliar a agenda política, propiciando a participação da sociedade civil em todos os ramos da sociedade.

Como os Partidos não garantiam a efetividade dos direitos de cidadania nem da democracia, os Movimentos Sociais lutam pelo Poder, em via democrática legítima.

\footnotetext{
${ }^{3}$ PAIVA, op. cit, p. 23.

${ }^{4}$ PAIVA op. cit. p. 24.

${ }^{5}$ Ibidem p. 24.

${ }^{6}$ DAGNINO E. Cultura, cidadania e democracia: a transformação dos discursos e práticas na esquerda latino-americana. Em Cultura e Política nos Movimentos Sociais Latino Americanos: Novas Leituras, (Sônia Alvarez, Evelina Dagnino e Arturo Escobar, orgs.) Editora da UFMG, 2000.

${ }^{7}$ DAGNINO op. cit. p. 23.
} 
O processo de renovação político-teórico que surge com o processo de redemocratização no Brasil contribuiu para romper as amarras que o marxismo tradicional impunha à análise de cultura e sua relação com a transformação social necessária. Trouxe também mudanças conceituais ao campo específico da análise cultural.

Alves ${ }^{8}$ refere que "a concepção do real é um processo dialético, onde se obtém a consciência crítica através da disputa de hegemonias contrastantes, um conflito no campo da ética e no campo político".

Os movimentos populares passam a compreender a necessidade de luta a partir do momento que não mais apenas aceitam direitos a moradia, saúde, educação e etc., mas sim objetivam o direito a ter direitos.

A Política Cultural é, então, um laço constitutivo entre Cultura e Política. Essa redefinição da Política implica que a Cultura deva ser entendida como concepção de um conjunto de significados que integram as práticas sociais totais, dinâmica propensa a câmbios vindos das lutas da Sociedade Civil.

O processo de redemocratização deu novo ânimo à sociedade brasileira, sobretudo aos que de alguma forma sentiam-se fora do arcabouço jurídico institucional, pseudo-cidadãos, que quando muito depositavam seu voto nas urnas a cada dois anos e aguardavam ser chamados a usufruir das riquezas produzidas e dos direitos a uma justiça igualitária e a políticas que abrangessem a totalidade da população menos favorecida.

"Essa mesma população antes colocada de lado, excluída do processo decisório e do acesso a uma vida decente em sociedade, que aproveitou o campo democrático para colocar em marcha a sua luta por direitos" "9. A Constituição de 1988 uma conquista coletiva e merecida, fruto da mobilização de toda uma sociedade, que após a conquista democrática tem na luta pela igualdade de direitos das minorias seu projeto mais importante.

Entender desenvolvimento humano de uma forma substantiva é aliar crescimento econômico a direitos sociais, civis e políticos, como afirma Amartya Sen. A formação da sociedade brasileira, abordada aqui a partir da argumentação de Paiva ${ }^{10}$ e Dagnino ${ }^{11}$ mostra que

\footnotetext{
${ }^{8}$ ALVES, Ana R. Cavalcanti. O Conceito de Hegemonia: de Gramsci a Laclau e Mouffe. In: Revista Lua Nova, n. 80, pp.71 - 96. São Paulo, 2010.

${ }^{9}$ DAGNINO E. Cultura, cidadania e democracia: a transformação dos discursos e práticas na esquerda latino-americana. Em Cultura e Política nos Movimentos Sociais Latino Americanos: Novas Leituras, (Sônia Alvarez, Evelina Dagnino e Arturo Escobar, orgs.) Editora da UFMG, 2000.

${ }^{10}$ PAIVA, Ângela M. de Randolpho. Direitos, desigualdade e acesso à universidade. In: Revista O Social em Questão. PUC/Rio, 2010. p. 20.

${ }^{11}$ Idem DAGNINO, 2004.
} 
o Brasil teve problemas em várias etapas da sua construção, e que somente a partir da década de 1980 vem se desenhando pelo processo democrático instituindo garantias de estabilidade institucional.

Encaminhada à questão democrática, o Brasil só conseguiu equalizar seus problemas econômicos internos e externos a partir do Plano Real, 1994, que atacou a hiperinflação, e colocou o país em condições de estruturar um futuro estável.

Ao abordar o desenvolvimento brasileiro, usando o modelo de Amartya Sen, pode-se afirmar que o Brasil está em uma tendência ascendente de crescimento econômico, melhorias da qualidade de vida, avanços no campo educacional, sistema de saúde universalizado, sistema político democrático consolidado, instituições formatadas e liberdades de participação civil. Quantitativamente avançou-se e melhorou-se a qualidade de participação da sociedade, mas tem-se muito a caminhar rumo a uma sociedade realmente, nacionalmente, justa.

\section{DEMOCRACIA}

Democracia é um sistema ou regime que se baseia na concepção da soberania popular e na distribuição equilibrada do poder, e que atribui o direito ao voto e, pela divisão dos poderes, o controle dos meios de decisão e execução. No Brasil isso nunca existiu efetivamente. Desde que o pais se tornou uma república, ainda não chegou-se a uma democracia substancial, mas somente um regime democrático formal. Os sucessivos governos civis, tidos como democráticos, desde então favoreceram - com a implementação de políticas públicas injustas o aumento da desigualdade social e da miséria. O que realmente existe é um grupo de autoridades elitistas e políticas que dirigem, governam e comandam o povo.

No caso do Brasil, a Democracia, de fato, só é exercida quando a maioria dos eleitores vai até as urnas e elegem os seus representantes. O acontecimento de o povo poder votar livremente nas eleições não significa que ele exerça controle sobre o governante. Ele elege, mas não pode exonerar e nem exigir que os governantes cumpram seus deveres constitucionais no que diz respeito à saúde, educação, moradia, previdência. Tudo isso fica a critério dos governantes e isso, claramente, não é democracia. Logo, apenas a prática eleitoral não implica, necessariamente, numa sociedade democrática ${ }^{12}$.

${ }^{12}$ SEN, Amartya. Desigualdade reexaminada. Rio de Janeiro: Record, 2001. 
Para Lima ${ }^{13}$ "a democracia declara os direitos universais do homem e do cidadão, mas a sociedade está estruturada de tal forma que tais direitos não existem de fato para a maioria da população". Destarte, a democracia é um procedimento que para ser pleno precisa de uma prática intensiva de cidadania, distribuição de renda e maior participação da sociedade nas decisões do governo.

Dentre os notáveis acontecimentos do século passado está o reconhecimento da Democracia, como forma de governo aceitável, pois é um modelo de governo maleável, que se ajusta a qualquer nação.

Mesmo diante da aceitação da democracia como modelo de governo, sua eficácia em países pobres ainda é questionável. A democracia, para alguns, tem sido menos eficiente que alguns governos autoritaristas, no que diz respeito ao desenvolvimento econômico e promoção do crescimento. Do outro lado há os que defendem a ideia de que ela está fundamentada em valores ocidentais, o que inviabiliza seu uso em outras sociedades.

Para o filosofo John Rawls a democracia não tem de ser vista apenas em termos de cédulas e votos, mas em termos de "racionalidade pública", discussão pública e encontro racional. Na política Rawls afirma que a objetividade exige uma estrutura pública de pensamento que seja capaz de proporcionar uma visão de concordância de julgamento entre agentes racionais. Mas para que essa racionalidade seja atingida é necessário que os indivíduos tenham vontade política de ir além de seus interesses pessoais.

A partir do conhecimento do "eixo central da democracia", o autor procura, em seguida, refutar a ideia de que a democracia é uma ideia essencialmente ocidental. Mesmo a tradição dos debates públicos, a pratica da eleição por meio de votos terem surgido na Grécia Antiga, caracterizando o início de um modelo democrático, não há espaço para afirmar que a democracia é um objeto ocidental.

$\operatorname{Sen}^{14}$ refere que respeito da eficácia da democracia, o autor busca refutar a afirmação de que esta seria menos efetiva no crescimento econômico que regimes autoritários, partindo da ideia de que os direitos democráticos estão entre os componentes constitutivos do desenvolvimento e não podem ser qualificados pela sua contribuição à economia, mas são constituintes do bem estar dos cidadãos, independentemente de serem ricos ou pobres.

\footnotetext{
${ }^{13}$ LIMA, Licínio C. Organização escolar e democracia radical: Paulo Freire e a governação democrática da escola pública. São Paulo, Cortez, 2000.

${ }^{14}$ SEN, Amartya. A Ideia de justiça. São Paulo: Companhia das Letras, 2011.
} 
Em seguida, a alegação que a democracia e crescimento econômico são palavras que não podem ser conjugadas na mesma sentença se dá pelos exemplos como Coréia do Sul e Cingapura. O sucesso econômico de uma nação está relacionado ao clima de mercado favorável, questões de segurança humana e não à forma de governo adotada.

\subsection{A Importância da Democracia}

O texto "A importância da democracia", de Amartya Sen, defende que a democracia é a melhor forma de escolha de governo e para sustentar sua tese ele utiliza três argumentos que defendem a democracia e contrapõe a liberdade democrática com a situação de miséria econômica que alguns países vivem.

Assim, nessa linha de raciocínio Amartya analisa que mesmo havendo desenvolvimento econômico em alguns países autoritários do continente asiático, a liberdade democrática ainda é melhor por três motivos principais: sua importância intrínseca em desenvolver capacidades humanas básicas como participação política e social; suas contribuições instrumentais, pois com a democracia é possível aumentar as oportunidades das pessoas falarem e se expressarem, expressando inclusive suas necessidades econômicas básicas, etc.; e, por último, o papel construtivo que a democracia possui, uma vez que o governo democrático se torna mais próximo de sua população e pode compreender melhor os desejos da mesma.

Sen ${ }^{15}$ ainda demonstra que a democracia não é só um sistema de governo melhor do que os governos autoritários, mas também uma janela de oportunidades para que os cidadãos que vivem em liberdade democrática possam desenvolver suas capacidades básicas como seres humanos, através da participação dos mesmos na esfera da coisa pública, tanto com relação a votos em eleições, como outras formas de participação política direta. Esse elemento propiciaria todos os cidadãos a fazerem a democracia funcionar por meio da participação de pessoas comuns.

Sem ${ }^{16}$ confirma a liberdade democrática como a melhor maneira de se governar, liberdade essa que deve ser respeitada mesmo em países com populações em estado de miséria, e elabora um raciocínio que demonstra como a liberdade democrática pode promover o fim de fomes coletivas e sanar muitas necessidades econômicas de populações em países pobres, como

\footnotetext{
${ }^{15}$ SEN, Amartya. Sobre ética e economia. São Paulo: Companhia das Letras, 1999.

${ }^{16}$ Ibidem. p. 87.
} 
tem acontecido com a Índia, afirma o indiano. Porém, para isso o economista defende que é necessário que as pessoas entendam a necessidade de sua participação na política de seu país.

\subsection{Educar para a Democracia}

A educação para a cidadania que forma o cidadão participativo, democrático e solidário, consciente de seus deveres e direitos, precisa se associar à educação em direitos humanos. "Não existe democracia sem direitos humanos, assim como não existem direitos humanos sem a prática da democracia"17.

A educação emancipadora cria condições para a superação de valores e costumes arraigados, decorrentes de vários fatores historicamente definidos: passasse por um longo período de escravidão, que significou exatamente a violação de todos os princípios de respeito à dignidade da pessoa humana, a começar pelo direito à vida; o sistema de ensino autoritário, elitista e com uma preocupação muito mais voltada para a moral privada do que para a ética pública; a complacência com a corrupção, dos governantes e das elites, assim como em relação aos privilégios concedidos aos cidadãos ditos de primeira classe ou acima de qualquer suspeita; o descaso com a violência, quando ela é exercida exclusivamente contra os pobres e os socialmente discriminados; as práticas religiosas essencialmente ligadas ao valor da caridade em detrimento do valor da justiça; o sistema familiar patriarcal e machista; a sociedade racista e preconceituosa contra todos os considerados diferentes; o desinteresse pela participação cidadã e pelo associativismo solidário; o individualismo consumista, decorrente de uma falsa ideia de "modernidade" 18 .

O mundo ao avesso ensina a padecer a realidade ao invés de transformá-la, a esquecer o passado ao invés de escutá-lo e a aceitar o futuro ao invés de imaginá-lo.

Pode-se e deve-se fazer da escola esse espaço da promoção e da vivência dos valores da liberdade, da justiça, da solidariedade, da cooperação, da tolerância e da paz. Criar, influenciar, compartilhar e consolidar mentalidades, costumes, atitudes, hábitos e comportamentos que respeitem o direito à vida. Propiciar aos educandos o desenvolvimento da capacidade de perceber as consequências pessoais e sociais de suas escolhas. Construir o senso de responsabilidade. Tornar o cidadão participante, crítico, responsável e comprometido com a

\footnotetext{
${ }^{17}$ BENEVIDES, Maria Victória. Educação em Direitos Humanos. In: Seminário de Educação em Direitos Humanos. São Paulo, 2000. p. 23

18 Ibidem. p. 27.
} 
mudança das práticas e condições da sociedade que violam ou negam os direitos humanos é fundamental para um país democrático e justo.

Deve-se oferecer à população espaços de exercício da cidadania. Garantindo a oportunidade de aprender a ser democrático, a ser solidário, a acreditar na capacidade de cada um na mudança. Criando condições para que os professores, os pais, a comunidade, os alunos tomem para si o destino da sua escola, para que sejam sujeitos ativos na elaboração do projeto político-pedagógico com que sonham. É fundamental aprender a falar em público, a vivenciar o conflito como espaço de aprendizagem, a defender ideias, a se organizar e a se articular para viabilizar uma proposta, a escolher seus representantes, a avaliar coletivamente, a reorientar a prática quando a avaliação apontar essa necessidade ${ }^{19}$.

A democratização da gestão implica não só o acesso da população à educação, mas também a participação desta na tomada de decisões que dizem respeito a seus interesses. Isso pressupõe distribuição do poder centralizado do Estado para as instâncias da base da pirâmide estatal onde se dá o contato direto com os cidadãos, desenvolvendo na sociedade os mecanismos necessários para levar o Estado a, cada vez mais, agir de acordo com os interesses dos cidadãos e das cidadãs.

\section{SUSTENTABILIDADE}

A palavra da moda atualmente é sustentabilidade. Em todos os setores, seja no meio ambiente, na economia, educação ou administração pública, todo mundo cita o termo sustentabilidade. E o que significa sustentabilidade? O que é ser sustentável? Teoricamente o termo "sustentável" tem origem do Latim: "sustentare", que significa sustentar, favorecer e conservar.

Mundialmente a palavra sustentabilidade começou a ser propagada a partir da realização da Conferência das Nações Unidas sobre o Meio Ambiente Humano - United Nations Conference on the Human Environment (UNCHE), em junho de 1972, em Estocolmo. A partir deste evento, que foi o primeiro encontro mundial promovido com o objetivo de discutir assuntos relacionados ao meio ambiente e soluções para a preservação da humanidade, o conceito de sustentabilidade passou a ganhar uma maior importância. No Brasil, a expressão

\footnotetext{
${ }^{19}$ SEN, Amartya. Desenvolvimento como liberdade. Tradução Laura Teixeira Motta; revisão técnica Ricardo Doniselli Mendes. São Paulo: Companhia das Letras, 2000.
} 
"sustentabilidade", ganhou dimensões maiores após a realização da Conferência sobre Meio Ambiente e Desenvolvimento (ECO), em 1992, no Rio de Janeiro.

O grande marco para o desenvolvimento sustentável mundial foi, sem dúvida a Conferência das Nações Unidas sobre Meio Ambiente e Desenvolvimento, realizada no Rio de Janeiro em junho de 1992 (a Rio 92), onde se aprovaram uma série de documentos importantes, dentre os quais a Agenda 21, um plano de ação mundial para orientar a transformação desenvolvimentista, identificando, em 40 capítulos, 115 áreas de ação prioritária. A Agenda 21 apresenta como um dos principais fundamentos da sustentabilidade o fortalecimento da democracia e da cidadania, através da participação dos indivíduos no processo de desenvolvimento, combinando ideais de ética, justiça, participação, democracia e satisfação de necessidades.

Dentre alguns dos focos discriminados na Agenda 21, pode-se destacar:

- Cooperação internacional;

- Combate à pobreza;

- Mudança dos padrões de consumo;

- Habitação adequada;

- Integração entre meio ambiente e desenvolvimento na tomada de decisões;

- Proteção da atmosfera;

- Abordagem integrada do planejamento e do gerenciamento dos recursos terrestres;

- Combate ao desflorestamento;

- Manejo de ecossistemas frágeis: a luta contra a desertificação e a seca;

- Promoção do desenvolvimento rural e agrícola sustentável;

- Conservação da diversidade biológica;

- Manejo ambientalmente saudável dos resíduos sólidos e questões relacionadas com os esgotos;

- Fortalecimento do papel das organizações não governamentais: parceiros para um desenvolvimento sustentável;

- Iniciativas das autoridades locais em apoio à agenda 21 a comunidade científica e tecnológica;

- Fortalecimento do papel dos agricultores;

- Transferência de tecnologia ambientalmente saudável, cooperação e fortalecimento; institucional a ciência para o desenvolvimento sustentável;

- Promoção do ensino, da conscientização e do treinamento. 
Na prática, a sustentabilidade está definida como a capacidade que o indivíduo ou um grupo de pessoas tem em se manterem dentro de um ambiente sem causar impactos a esse ambiente. Mas apesar da sustentabilidade estar associada diretamente ao meio ambiente e a tudo o que envolve este, não está limitado somente a esta área.

A sustentabilidade também está relacionada a outros setores da sociedade como a economia, a educação e a cultura. A sustentabilidade está diretamente ligada ao desenvolvimento de vários setores da sociedade, sem que estes agridam o meio ambiente. É através da sustentabilidade que os recursos naturais são utilizados de forma inteligente e são preservados para as gerações futuras. Sustentabilidade é isto, é saber suprir as necessidades presentes sem interferir nas gerações futuras ${ }^{20}$.

Um conceito correto e amplo de sustentabilidade está associado a soluções, caminhos e planos que busquem resgatar adoções de práticas sustentáveis na vida de cada pessoa e atinjam uma melhora comum a todos. Contribuir com as vivências e experiências pessoais e repassar estas ao coletivo é um fator decisivo para possibilitar a prática da sustentabilidade. A adoção de práticas sustentáveis resulta a médio e longo prazo numa nova perspectiva de vida para os sucessores e lhes garantirão a manutenção dos recursos naturais necessários para uma melhor qualidade de vida.

A falta de conhecimento do ser humano em relação à sustentabilidade e ao que isto implica, pode ter consequências catastróficas. Nos dias de hoje é preciso que cada indivíduo tenha a consciência de que é necessário se preocupar e cuidar do meio ambiente no qual se vive. E para isto, é preciso estar atento a cada atitude e repensar a forma como se vive dentro deste ambiente. A continuação e sobrevivência da raça humana estão totalmente dependentes da conservação dos recursos naturais de nossas matas, florestas, rios, lagos e oceanos.

Para Amartya Sen a sustentabilidade é ser ético e solidário. A Sustentabilidade não deve acontecer somente no ambiente físico e material, é necessário manter a vida que está presente em todos.

Amartya Sen toma como ponto de partida o fato de que a exploração contínua e exagerada dos recursos naturais compromete a saúde do planeta e a vida das futuras gerações. E a economia é responsável por grande parte dessa exploração, já que se vale da natureza no processo produtivo e no beneficiamento de produtos.

\footnotetext{
${ }^{20}$ SEN, Amartya. Desenvolvimento como liberdade. Tradução Laura Teixeira Motta; revisão técnica Ricardo Doniselli Mendes. São Paulo: Companhia das Letras, 2000.
} 
Para o autor o desenvolvimento sustentável esta ligado á propriedade regenerativa do sistema ecológico frente ao uso irrestrito dos recursos naturais escassos.

\subsection{Sustentabilidade e suas Implicações para Educação}

As duas últimas décadas testemunhou-se o surgimento do discurso da sustentabilidade. A palavra sustentabilidade tornou-se palavra mágica, falado por diferente sujeito e envolve os diversos contextos sociais e assumindo muitos sentidos.

Essa expressão "sustentabilidade" tem influência no campo de atividade diversa entre as quais o campo da educação, os organismos internacionais, as organizações não governamentais e na política pública dirigidos a educação, ambiente e desenvolvimento de alguns países.

Há uma tendência a substituir a concepção de educação ambiental, até então dominante, por uma nova proposta “educação para a sustentabilidade" ou "para um futuro sustentável".

Essa renovação pode ser observada nas conferencias da Unesco, na agenda 21 na rio92, gradualmente o novo discurso passou a penetrar outros países centrais e periféricos e nas demais esfera institucionais.

À medida que o debate da sustentabilidade vai se tornando mais complexo e difundido socialmente, ele vai sendo apropriado por diferentes forças sociais que passam a lhe imprimir o significado que melhor expressa seus valores e interesses particulares.

A educação para a sustentabilidade surgiu como uma tentativa de superar alguns problemas apresentado pela educação ambiental praticado nas escolas de diversos países da união europeia, como a Itália, a Espanha e outros.

A educação ambiental assumiu expressões reducionistas em vários aspectos ao tratar a crise ambiental como uma crise meramente ecológica; ao confundir o meio ambiente com a natureza; ao desprezar suas dimensões políticas, éticas e culturais. Portanto, a partir de uma crítica e de um diagnóstico da educação ambiental experimentadas em muitas escolas europeias ao longo das últimas décadas, chegou-se a nova proposta de educação para a sustentabilidade ou para o desenvolvimento sustentável.

A educação ambiental brasileira, sobretudo a partir da década de 90, vem desenvolvendo iniciativas teóricas e práticas renovadoras que se empenham em superar tanto a herança naturalista prove mente das ciências naturais quanto as visões reducionistas e politicamente conservadoras que estiveram presentes na formação do campo no brasil. 
Entende-se que a educação pressupõe autonomia e pensamento crítico. Para ele, os alunos deveriam ser estimulados a pensar, jugar e se comportar por si próprio e não orientadas para uma finalidade pré-determinada. Uma educação orientada para uma finalidade determinada sugeri mais um treinamento para aquisição de certas habilidades do que um aprendizado envolvido com a compreensão.

Logo, a discursão visa revelar a diversidade de divisões de mundo envolvidas no debate, de modo que os alunos não sejam "educados para a sustentabilidade", mas capacitados a comparar, debater e julgar por si próprios as diversas posições manifestas no debate a aquelas que lhes parecem mais sensatas. Pode-se dizer que se trata de uma abordagem educacional, pois a outra, ao procurar "educação para algo", perde o sentido educativo.

\subsection{Por uma Ecopedagogia}

A UNESCO patrocinou em 1997 na Tessalônica (Grécia) uma conferência internacional sobre 'meio ambiente e sociedade', centrada no tema da educação. A Conferência da Tessalônica seguiu os passos das reuniões anteriores da Unesco - Tbilisi (1977), Jomtien (1990), Toronto (1992), Istambul (1993) - e a série de conferências das Nações Unidas iniciada em 1992 com a Rio-92, seguida pelas de 1994 no Cairo (população), em 1995 em Copenhague (desenvolvimento social) e Beijing (sobre a mulher) e de 1996 em Istambul (assentamentos humanos).

Três anos antes, a UNESCO havia lançado a iniciativa internacional sobre 'educação para um futuro sustentável', reconhecendo que a educação era a 'chave' do desenvolvimento sustentável e autônomo. O desenvolvimento sustentável tem um grande componente educativo: a preservação do meio ambiente depende de uma consciência ecológica e a formação da consciência depende da educação.

É aqui que entra em cena a ecopedagogia. Ela é uma pedagogia da vivência cotidiana com o outro, portanto, democrática e solidária. A pedagogia tradicional centrava-se na espiritualidade, a pedagogia da escola nova, na democracia e a tecnicista, na neutralidade científica. A ecopedagogia centra-se na relação entre os sujeitos que aprendem juntos "em comunhão".

A ecopedagogia é um movimento que ocorre muito mais fora da escola do que dentro dela, tentando suprir uma lacuna que a educação ambiental deixou ao se limitar ao ambiente 
externo, ao deixar de confrontar os valores sociais e ao não por em questão o aspecto político da educação e do conhecimento.

A sustentabilidade é um princípio reorientador da educação e principalmente dos currículos, objetivos e métodos. Colocada neste sentido, a ecopedagogia não é uma pedagogia a mais, ao lado de outras pedagogias. Ela só tem sentido como projeto alternativo global, em que a preocupação não está apenas na preservação da natureza (ecologia natural) ou no impacto das sociedades humanas sobre os ambientes naturais (ecologia social), mas num novo modelo de civilização sustentável do ponto de vista ecológico (ecologia integral) que implica uma mudança nas estruturas econômicas, sociais e culturais. Ela está ligada, portanto, a um projeto utópico: mudar as relações humanas, sociais e ambientais que temos hoje. Aqui está o sentido profundo da ecopedagogia, ou de uma pedagogia da Terra.

Foi durante a realização do Fórum Global 92, no qual se discutiu muito a educação ambiental, que se percebeu a importância de uma pedagogia do desenvolvimento sustentável ou de uma ecopedagogia.

Hoje, porém, a ecopedagogia tornou-se um movimento e uma perspectiva da educação maior do que uma pedagogia do desenvolvimento sustentável. Ela está mais para a educação sustentável, para uma eco educação, que é mais ampla do que a educação ambiental. A educação sustentável não se preocupa apenas com uma relação saudável com o meio ambiente, mas com o sentido mais profundo do que fazemos com a nossa existência, a partir da vida cotidiana. A ecopedagogia não se opõe à educação ambiental. Ao contrário, para a ecopedagogia a educação ambiental é um pressuposto. A ecopedagogia a incorpora e oferece estratégias, propostas e meios para a sua realização concreta.

\subsection{O Papel de cada um na Sustentabilidade Ambiental}

Antigamente as maiores preocupações referiam-se apenas à poluição atmosférica e à contaminação da água e do solo por agrotóxicos, no entanto atualmente essa preocupação se expandiu para problemas ambientais mais generalizados como a desertificação, a degradação de florestas e edifícios causados pela chuva ácida, a contaminação tóxica da água e de alimentos que compõem a mesa dos cidadãos.

Cada vez mais urbanizadas, as cidades assumiram um papel considerável no meio ambiente global. Assim é indispensável reconhecer os problemas urbanos do mundo inteiro a 
fim de empenhar o cenário global na preservação dos ecossistemas e principalmente a camada de ozônio que estabelece muitos debates em todo o mundo.

A postura de dependência e de desresponsabilização da população decorre principalmente da desinformação, da falta de consciência ambiental e de um déficit de práticas comunitárias baseadas na participação e no envolvimento dos cidadãos, que proponham uma nova cultura de direitos baseada na motivação e na coparticipação da gestão ambiental ${ }^{21}$.

A relação entre homem/meio ambiente são estruturadas de maneira que a natureza disponibiliza uma infinita variação de recursos físicos que são utilizados para benefícios da população que devolve à natureza uma série de fatores causadores de poluição e desmatamento ecológico, estabelecendo um vínculo entre as duas partes onde a natureza possui a economia e a passa para a população e as pessoas devolvem como resíduos para o meio ambiente.

Assim, pressupõe que o meio ambiente e o homem estão em caminhos diferenciados, pois o homem necessita produzir cada vez e mantém a visão de que os recursos provenientes da natureza são infinitos, causando o maior problema mundial, o impacto ambiental.

Partindo do princípio que desenvolvimento sustentável é desenvolvimento que satisfaz as necessidades do presente sem comprometer a capacidade de as futuras gerações satisfazerem suas próprias necessidades, tornou-se necessário o consumo de recursos naturais finitos por esta geração juntamente com a preocupação de garantir que esses mesmos recursos estejam disponíveis para gerações futuras uma vez que são finitos.

Diversas necessidades e limitações foram encontradas neste processo, fazendo com que esta gestão passasse a demandar novas abordagens. A participação da sociedade começou a integrar as políticas e diretrizes de gestão desenvolvendo assim o processo de desenvolvimento regional sustentável a ser organizados num sistema integrado.

O meio ambiente, nos últimos anos, vem sendo exaustivamente discutido em função da degradação da natureza e consequente decadência da qualidade de vida, tanto nas cidades, como no campo. Essa situação decorre, entre outras razões, do mau gerenciamento ambiental advindo do setor público e privado ${ }^{22}$.

Nesta perspectiva, o processo de planejamento relacionado ao desenvolvimento regional sustentável, justifica-se pelo surgimento de uma nova percepção local e global de futuro comum, sendo considerado que as políticas públicas e a participação da sociedade podem ser

\footnotetext{
${ }^{21}$ JACOBI, Pedro. Educação Ambiental, Cidadania e Sustentabilidade. (2003)

Disponível em: http://www.scielo.br/pdf/cp/n118/16834.pdf. Acesso em: 30 jan. 2017. p. 193.

${ }^{22}$ SCHNEIDER, Evania. Gestão ambiental municipal: Preservação ambiental e o desenvolvimento sustentável. (2001). Disponível em: <http://www.portalga.ea.ufrgs.br/acervo/ds_art_05.pdf> Acesso em: 30 jan. 2016. p. 03.
} 
diretamente responsáveis pela evolução e transformação do meio social, econômico e ambiental.

As políticas públicas, notadamente aquelas voltadas para a educação e saúde, complementam as oportunidades abertas pelo comprometimento das instituições e pelas atividades econômicas, cobrindo lacunas e ajudando na superação das privações e na construção do cidadão agente, este, agora, capaz, de elevar o direito ao desenvolvimento sustentável, como efetivação prática.

Portanto, a educação é pedra fundamental para o desenvolvimento da personalidade crítica, capaz de analisar e compreender o meio ambiente como um bem de todos, e finito.

\section{CONSIDERAÇÕES FINAIS}

O presente artigo procurou discutir com base nos pensamentos do autor Amartya Sen sobre as práticas educativas, com intuito de aumentar os diversos sistemas de conhecimento numa perspectiva interdisciplinar. Dessa forma, fez uma reflexão sobre o processo educativo e a união de diversas áreas a fim de possibilitar novas praticas coletivas, numa perspectiva que permite o dialogo entre saberes.

Pode-se observar que a educação ambiental é a condição necessária para modificar um quadro de crescente degradação socioambiental, reforçando que é preciso criar novos estilos de vida e promover uma consciência ética que questione o atual modelo de desenvolvimento. $\mathrm{O}$ desafio é criar uma educação ambiental que seja critica e criativa em nível formal e não formal.

E que a partir de agora a educação deve impreterivelmente incluir as quatro grandes tendências da ecologia: a ambiental, a social, a mental e a integral ou profunda (aquela que discute o lugar na natureza). Mais e mais se impõem entre os educadores esta perspectiva: educar para o bem viver que é a arte de viver em harmonia com a natureza e propor-se repartir equitativamente com os demais seres humanos os recursos da cultura e do desenvolvimento sustentável.

Precisa-se estar conscientes de que não se trata apenas de introduzir corretivos ao sistema que criou a atual crise ecológica, mas de educar para sua transformação. Isto implica superar a visão reducionista e mecanicista ainda imperante e assumir a cultura da complexidade. Ela permite ver as inter-relações do mundo vivo e as eco dependências do ser humano. Tal verificação exige tratar as questões ambientais de forma global e integrada. Deste tipo de educação se deriva a dimensão ética de responsabilidade e de cuidado pelo futuro comum da 
Terra e da humanidade. Faz descobrir o ser humano como o cuidador de nossa Casa Comum e o guardião de todos os seres.

A educação ambiental é um desafio para a política da sustentabilidade, e exige um esforço de todos para um processo de fortalecimento da democracia e cidadania. É preciso estimular a reflexão sobre a diversidade em torno das relações individuo natureza e que cada um saiba da importância da responsabilidade para construir uma sociedade ambientalmente sustentável.

Sem infere a necessidade de que o conceito de desenvolvimento sustentável não caminhe somente pela órbita das necessidades humanas, de forma egoísta, mas instiga a pensar o meio ambiente como algo maior, intrínseco aos territórios essenciais da vida.

\section{REFERENCIA}

ALVES, Ana R. Cavalcanti. O Conceito de Hegemonia: de Gramsci a Laclau e Mouffe. In: Revista Lua Nova, São Paulo, n. 80, pp.71 - 96, 2010. BENEVIDES, Maria Victória. Educação em Direitos Humanos. In: Seminário de Educação em Direitos Humanos. São Paulo: Forense, 2000.

DAGNINO E. Cultura, cidadania e democracia: a transformação dos discursos e práticas na esquerda latino-americana. Em Cultura e Política nos Movimentos Sociais Latino Americanos: Novas Leituras, (Sônia Alvarez, Evelina Dagnino e Arturo Escobar, orgs.) Editora da UFMG, 2000.

Sociedad Civil, Espacios Públicos y Democratización: Brasil. Sociedade civil, participação e cidadania: de que estamos falando? Políticas de Ciudadania y Sociedad Civil en Tiempos de Globalización, Daniel Mato e Illia Garcia (coords.), Caracas: UCV, 2004.

JACOBI, Pedro. Educação Ambiental, Cidadania e Sustentabilidade, 2003. Disponível em: <http://www.scielo.br/pdf/cp/n118/16834.pdf>. Acesso em: 30 jan. 2017, 17:48:37.

LIMA, Licínio C. Organização escolar e democracia radical: Paulo Freire e a governação democrática da escola pública. São Paulo: Cortez, 2000.

PAIVA, Ângela M. de Randolpho. Direitos, desigualdade e acesso à universidade. In: Revista O Social em Questão. PUC/Rio, 2010.

SCHNEIDER, Evania. Gestão ambiental municipal: Preservação ambiental e o desenvolvimento $\quad$ sustentável, 2001. Disponível em: http://www.portalga.ea.ufrgs.br/acervo/ds_art_05.pdf. Acesso em: 30 jan. 2016, 20:21:39. SEN, A. KLIKSBERG, B. As pessoas em primeiro lugar: a ética do desenvolvimento e os problemas do mundo globalizado. São Paulo: Companhia das Letras, 2010.

SEN, Amartya. A Ideia de justiça. São Paulo: Companhia das Letras, 2011.

Desenvolvimento como liberdade. São Paulo: Companhia das Letras, 2010.

Rev. de Direito e Sustentabilidade | e-ISSN: 2525-9687 | Porto Alegre | v. 4 | n. 2 | p. 40 - 58 | Jul/Dez. 2018 
. Desigualdade reexaminada. Rio de Janeiro: Record, 2001.

Desenvolvimento como liberdade. Tradução Laura Teixeira Motta; revisão técnica

Ricardo Doniselli Mendes. São Paulo: Companhia das Letras, 2000.

Sobre ética e economia. São Paulo: Companhia das Letras, 1999. 